\title{
RESOLUTION OF SEVERE RECALCITRANT FACIAL ATOPIC DERMATITIS WITH TOPICAL TACROLIMUS
}

\author{
SL Walker, SpR; Vicky Yates, Consultant, Dermatology \\ Royal Lancaster Infirmary
}

A four-year-old girl has been attending the department of dermatology since the age of nine months with severe facial atopic dermatitis (AD) (Figure 1). It proved difficult to control despite treatment with numerous topical corticosteroids of varying potencies, either alone or in combination with topical antiseptics and antibiotics. Frequent courses of oral antibiotics were required to treat secondary bacterial infection of the eczematous areas. She then developed eczema herpeticum of her face and required a course of oral aciclovir. Relapse was rapid and so in addition to the application of topical steroids it was necessary to maintain her on prophylactic oral aciclovir and erythromycin to suppress the infective agents which were driving the eruption.

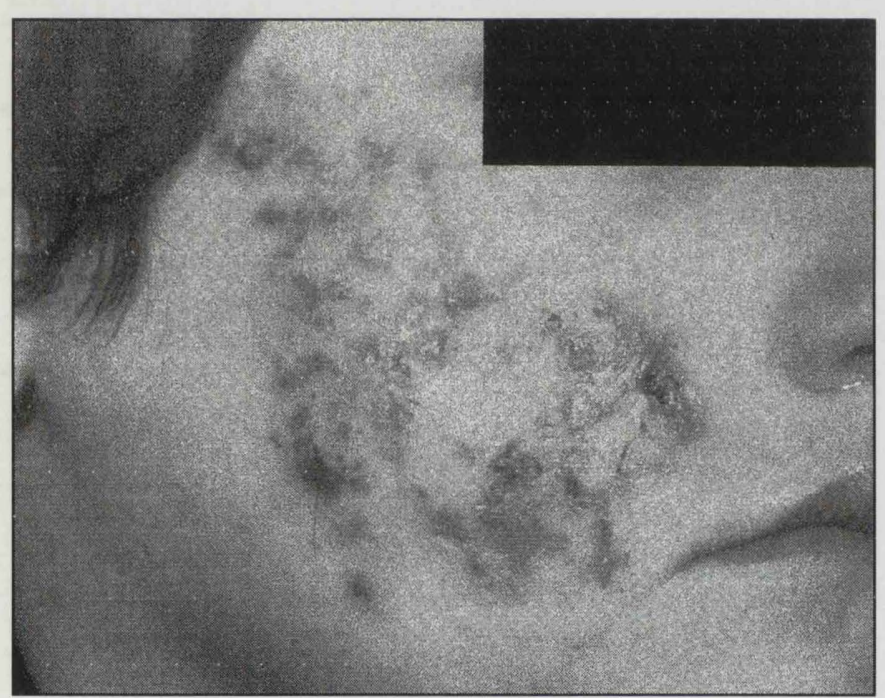

Figure 1

Her facial eruption caused her a great deal of discomfort and some problems with socialising. It was resistant to standard topical therapy even when applied by trained nursing staff in hospital or in the community. The decision was taken to try a new topical agent - tacrolimus ointment. This was obtained on a named-patient basis after approval by the Drug and Therapeutics Committee and within a week it had produced dramatic improvement (Figure 2) of symptoms and signs. This persists and has allowed the antibiotics to be stopped.

Tacrolimus is a macrolide produced by Streptomyces tsukubaensis and has similar modes of action to ciclosporin, the best known immunomodulator of this group ${ }^{(1)}$. It has the advantage that its smaller molecule can be absorbed through the epidermis, thus allowing it to be used topically. Systemic absorption is minimal ${ }^{(2)}$. Tacrolimus does not cause skin atrophy ${ }^{(2)}$, a major problem when prescribing conventional topical steriod therapy for severe chronic inflammatory dermatoses, particularly on sites such as the face and neck.

The most common side effect reported with the use of topical tacrolimus is a transient burning sensation localised to

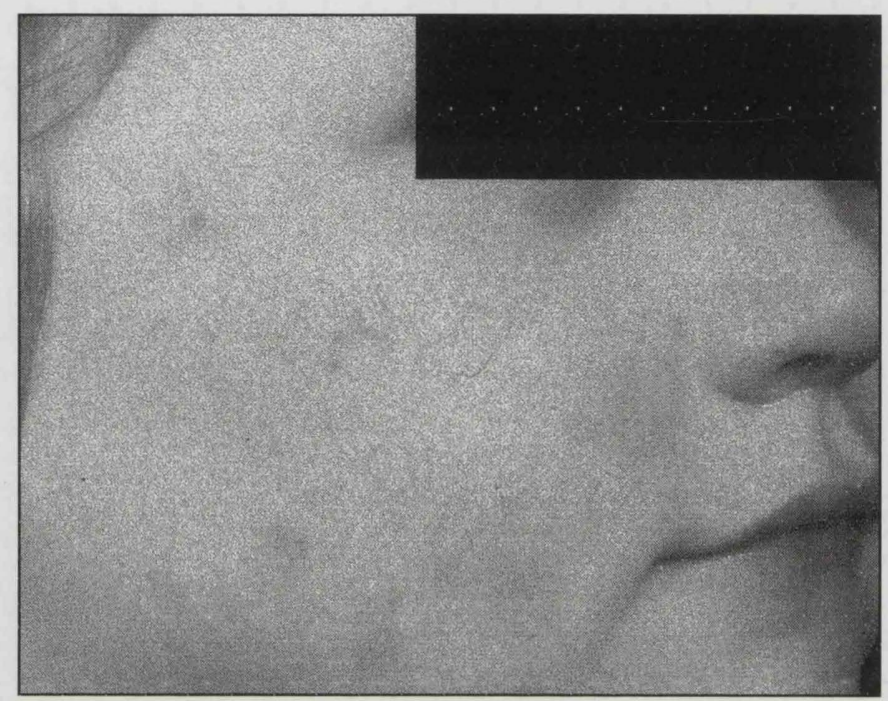

Figure 2

the site of application. There is no evidence to suggest an increase in cutaneous infections ${ }^{(2)}$ but as with other immunosuppressant agents there may be an increased risk of cutaneous malignancy in the long term which requires further monitoring.

There is great optimism (with a sound evidence base) that tacrolimus and other topical immunomodulators will eventually supersede topical corticosteroids in the treatment of $\mathrm{AD}$, reducing disabling symptoms and unwanted adverse effects, particularly skin atrophy. It may also have a role in the management of oral and perineal Crohn's disease ${ }^{(3)}$.

Tacrolimus will significantly improve the management of $\mathrm{AD}$ resistant to topical steriods and prevent many people requiring systemic immunosuppression. As with many innovative treatments cost is a problem: $50 \mathrm{~g}$ of tacrolimus costs approximately $£ 200$, compared to $£ 12$ for the most expensive steriod-containing preparation. The cost will become more reasonable once the preparation becomes commercially available in the UK. In carefully selected individuals it will undoubtedly bring huge benefit and by reducing morbidity prove cost effective.

\section{Acknowledgement \\ Thanks to Jim Latona, Pharmacy, RLI.}

\section{REFERENCES}

1 Smith $\mathrm{CH}$. New approaches to topical therapy. Clin Exp Dermatol 2000;25:567-74

2 Paller A, Eichenfield LF, Leugh DYM et al A 12-week study of tacrolimus ointment for the treatment of atopic dermatitis in pediatric patients. J Am Acad Dermatol 2001;33:S47-57

3 Casson DH, Eltumi M, Tomlin S et al Topical tacrolimus may be effective in the treatment of oral and perineal Crohn's disease. Gut 2000;47:436-40 